“O heroísmo cavaleiresco dos séculos XV-XVII”, en Revista Signum, 2013, vol. 14, n. 2, pp. 222-233

ISSN: 21777306

Revista Signum, 2013, vol. 14, n. 2.

\title{
O HEROÍSMO CAVALEIRESCO DOS SÉCULOS XV-XVII ${ }^{1}$
}

\section{THE CHIVALRIC HEROISM OF THE XVTH-XVIITH CENTURIES}

\author{
Aurelio Vargas Díaz-Toledo \\ University College Dublin
}

Resumo: Após conhecer o modo por que se realizou a configuração ficcional do heroísmo cavaleiresco durante a Idade Média (com base no Livro do cavaleiro Zifar e no Amadis de Gaula), ao longo da nossa intervenção procuramos analisar como as características tradicionais, arquetípicas e míticas, que se vinham concedendo ao herói dos livros de cavalarias, vão-se transformando à medida que acaba o século XV e avança o século XVI. E estas transformações têm a ver com uma perda da autenticidade que converte os protagonistas destas obras literárias em seres estereotipados, até abstratos, longe dos seus modelos medievais e mais próximos das personagens de caráter sentimental, cujas preocupações irão girando em torno dos amores, aos quais servem as virtudes próprias do herói mítico, isto é, a firmeza, a fortaleza, a grandeza de alma, a nobreza e o valor. Para isso, analisaremos alguns dos livros dos ciclos de cavalarias do Amadis de Gaula e do Palmeirim, sem esquecer livros de cavalarias portugueses como o Palmeirim de Inglaterra, de Francisco de Moraes, e suas continuações.

Palavras-chave: heroísmo; livros de cavalarias; séculos XV-XVII.
Abstract: After knowing better the fictional setting of chivalrous heroism during the Middle Ages (based on the Livro do cavaleiro Zifar and Amadis de Gaula), along our intervention we seek to analyze how the traditional features, archetypal and mythical, of the hero of the books of chivalry, are in a continuous transformation through the end of fifteenth century and the sixteenth century. And these changes have to do with a loss of authenticity that converts the protagonists of these literary works in people stereotyped, away from their medieval models and closer to the characters of sentimental character, whose concerns will revolve around the loves, which serve the virtues of the mythical hero, ie, firmness, fortitude, magnanimity, nobility and courage. For this, we analyze some of the books of chivalry cycles of Amadis de Gaula and Palmeirim, without forgetting Portuguese books of chivalry as Palmeirim de Inglaterra, by Francisco de Moraes, and its sequels.

Keywords: heroism; romances of chivalry; XVXVIIth Centuries.

Recebido em: 17/10/2013

Aprovado em: 07/12/2014

\footnotetext{
1 Este trabalho está inserido no Concurso Investigador FCT 2012 (Ref. IF/01502/2012): Base de dados interactiva sobre a Matéria Cavalereisca Portuguesa dos séculos XVI-XVIII, desenvolvido no Seminário Medieval de Literatura, Pensamento e Sociedade (SMELPS), do Instituto de Filosofia da Universidade do Porto (UI\&D 502). Gostaríamos também de agradecer a Isabel CORREIA a revisão do artigo.
}

${ }^{2}$ E-mail: ifilosofia2@letras.up.pt 
A partir da ideia estruturalista de que todos os relatos possuem ao menos três elementos invariáveis, um Sujeito, uma Ação e um Objeto, o professor Javier Roberto González tem analisado a configuração ficcional do heroísmo cavaleiresco na Idade Média. Para isso tem utilizado como hipótese de trabalho a teoria das três matrizes narrativas: a cosmogônica, a heroica e, por último, a romancesca ${ }^{3}$. Graças a ela foi-lhe possível estabelecer que as distintas realizações do heroísmo cavaleiresco e cortesão do romance arturiano e das primeiras manifestações ibéricas dos livros de cavalarias, isto é, o Livro do cavaleiro Zifar e o Amadis de Gaula primitivo, aparecem situadas entre a matriz puramente heroica do cantar de gesta e a matriz romancesca do exemplum didático. Em todos os casos, trata-se de heróis cujo mundo se impõe a eles ora por fracassar pessoal, social ou politicamente tais como Lançarote, Tristão ou rei Artur-, ora por construir o seu projeto heroico a partir da aceitação das normas legais vigentes no mundo - como acontece no Zifar e no Amadis-.

Tendo em conta as conclusões do professor argentino em relação aos livros de cavalarias medievais, ao longo do nosso trabalho vamos continuar a linha temporal que ele demarcou e falar assim da transformação do heroísmo nos livros de cavalarias hispânicos dos séculos XV-XVII. Para levar a cabo este objetivo, é preciso assinalar que, dado o extenso corpus de mais de oitenta obras que forma parte do género cavaleiresco em Espanha e Portugal, este nosso trabalho basear-se-á num conjunto reduzido, mas muito representativo, de textos de cavalarias que, em qualquer caso, nos servirão para ilustrar a nossa ideia da perda do caráter heroico dos protagonistas destas histórias.

Entre as narrativas que selecionámos, figuram o Amadis de Gaula (1508) e as Sergas de Esplandião (1510), de Garci Rodríguez de Montalvo, o Florisando, de Rui Páez de Ribera (1510), as continuações amadisianas de Feliciano de Silva Lisuarte de Grecia (1514), Amadís de Grecia (1530) e as quatro partes do Florisel de Niquea (1532-1535-1551), todos eles do âmbito castelhano4; e, do lado portu-

\footnotetext{
${ }^{3}$ Teoria muito mais desenvolvida no seu recente livro Los Milagros de Berceo: alegoría, alabanza, cosmos. Buenos Aires: Miño y Dávila, 2013.

${ }^{4}$ Para as obras de Garci RODRÍGUEZ DE MONTALVO, tivemos em conta as edições seguintes: Amadís de Gaula. Ed. Juan Manuel Cacho Blecua. 3. ed. Madrid: Cátedra, 1996; e Las Sergas de Esplandián. Ed. Pascual de Gayangos. Madrid: M. Rivadeneyra, 1857 (Reimpresso em Madrid: Atlas, 1963). Para a Tercera parte de Florisel de Niquea, de Feliciano de Silva, usámos a edição de Javier MARTÍN LALANDA. Alcalá de Henares: Centro de Estudios Cervantinos, 1999. No que diz respeito ao resto de textos, usámos os guias de leitura seguintes, todos eles publicados em Alcalá de Henares, no Centro de Estudios Cervantinos: Amadís de Grecia, de Feliciano de Silva, por Carmen
} 
guês, o Palmeirim de Inglaterra (ca. 1542), de Francisco de Moraes, e suas continuações, a Terceira e Quarta Partes da Chrónica de Palmeirim de Inglaterra ou Duardos Segundo (1587), de Diogo Fernandes, e a Quinta e Sexta Partes de Palmeirim de Inglaterra ou Clarisol de Bretanha (1602), de Baltazar Gonçalves Lobato 5 .

O primeiro dos textos analisados é, como não podia ser de outro modo, aquele que dá origem ao género literário -e editorial6- dos livros de cavalarias, Los quatro libros del virtuoso cavallero Amadís de Gaula, cuja primeira edição conhecida é de 1508, impressa em Saragoça pelo alemão Jorge Coci. Contudo, sabemos da existência de um incunábulo datado, aproximadamente, de 1496.

Procedente de uma versão medieval, o Amadis, cujas características formais e temáticas vão ser logo imitadas, modificadas e ultrapassadas por diferentes autores ao longo do século XVI, deve a sua fortuna, tal e como o conhecemos hoje, a um nobre regedor da vila castelhana de Medina del Campo, Garci Rodríguez de Montalvo, que levou a cabo uma reescrita muito ambiciosa do "original corrupto" que caiu nas suas mãos. Segundo o professor Juan Manuel Cacho Blecua ${ }^{7}$, a refundição de Montalvo poderia resumir-se em quatro pontos essenciais e relacionados entre si: em primeiro lugar, terá corrigido os antigos originais; depois, terá inserido novas glossas doutrinais e exemplares; em terceiro lugar, terá adaptado narrativa, estilística e ideologicamente esses antigos originais aos novos tempos da corte dos Reis Católicos, eliminando, mudando e ampliando alguns episódios; e, finalmente, terá criado um texto completamente novo, ao qual acrescentou o quarto livro de Amadis e mais um quinto que intitulou as Sergas de Esplandião, protago-

LASPUERTAS, (2001); Lisuarte de Grecia, de Feliciano de Silva, por Emilio José SALES DASÍ (1998); e Florisel de Niquea (parte III), de Feliciano de Silva, por Javier MARTÍN LALANDA (1999).

${ }^{5}$ Para a obra de Diogo FERNANDES utilizámos a edição de Lisboa, Marcos Borges, 1587, exemplar da Biblioteca Nacional de Madrid: R-4796. Para o texto de Baltasar Gonçalves LOBATO, usámos a edição de Lisboa, Iorge Rodrigues, 1602, segundo o exemplar da Biblioteca do Cigarral do Carmen, em Toledo: TO. BI. 2-U3, NR 577. Com respeito à obra de Francisco de MORAIS, vimos a recente edição de ALPALHÃO, Margarida Maria de Jesus Santos. O amor nos livros de cavalarias- O Palmeirim de Inglaterra de Francisco de Moraes: Edição e Estudo. Lisboa: Universidade Nova de Lisboa, 2009. Também nos resultou útil a nossa edição: Palmerín de Inglaterra (Toledo, Herederos de Fernando de Santa Catalina, 1547). Ed. Aurelio Vargas Díaz-Toledo. Alcalá de Henares: Centro de Estudios Cervantinos, 2006.

6 Teoria desenvolvida no livro de: LUCÍA MEGÍAS, José Manuel. Imprenta y libros de caballerías. Madrid: Ollero \& Ramos, 2000.

${ }^{7}$ CACHO BLECUA, Juan Manuel. "Los cuatro libros de Amadís de Gaula de Garci Rodríguez de Montalvo". Amadís de Gaula 1508. Quinientos años de Libros de caballerías. Biblioteca Nacional de España: Sociedad Estatal de Conmemoraciones Culturales, 2008, pp. 129-158.

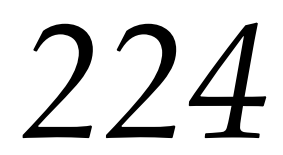


nizado pelo seu filho. Entre as grandes mudanças inseridas na nova adaptação de Montalvo figura a eliminação daquelas aventuras com final trágico nas quais Esplandião, sem o saber, matava o seu pai e causava indiretamente o suicídio da sua mãe, umas mortes que, provavelmente, eram um reflexo das tensões políticas vividas nas monarquias hispânicas durante as primeiras décadas do século XV.

Por tudo isto que acabámos de descrever, a versão de Montalvo pode interpretar-se como uma maneira de tratar de ultrapassar esta situação de desordem em que a cavalaria amadisiana estava condenada a fenecer, posto que os valores refletidos no Amadis de Gaula medieval -tais como a honra, a luta contra o infiel, a lealdade, a unidade e, sobretudo, a afirmação da autoridade régia-, continuavam a ser válidos na nova era que trouxe a chegada dos Reis Católicos, como consequência da vitória sobre o exército português, em 1479, e a guerra de Granada que acabou no ano de 1492. Com efeito, estes fatos históricos contribuem para difundir a ideia providencial da monarquia não só como símbolo da união e paz entre cristãos, mas também como defensores da santa fé católica perante a perigosa expansão dos inimigos muçulmanos ao longo do Mediterrâneo.

Deste modo, Montalvo dirige os seus esforços para a configuração de um novo modelo heroico que se adeque melhor ao sistema ideológico do seu tempo, uma nova cavalaria que estará representada na figura de um cavaleiro modelar, sem mácula, qual Galaaz, o filho de Lançarote do Lago, defensor da ordem, da disciplina e da cristandade. Referimo-nos, claro, a Esplandião. Para conseguir esse objetivo, Montalvo procura modificar a linha argumental que fazia com que Amadis morresse às mãos do seu filho, já que este último é um cavaleiro cristão que agora está ao serviço de Deus e não podia ser responsável por uma ação tão mesquinha do ponto de vista da moral cristã.

Para o autor de Medina del Campo, a figura de Amadis de Gaula nos três primeiros livros da obra representava um mundo cavaleiresco obsoleto, que era preciso deixar para atrás para que se desse lugar a um novo heroísmo de cariz mais religioso. A biografia de Amadis, e a dos cavaleiros da sua geração, estava marcada essencialmente por duas linhas temáticas mais ou menos paralelas e equitativas entre si: a façanha guerreira e o serviço amoroso. No que concerne a primeira, o herói procurava conseguir a fama terrena mediante o exercício das armas, de tal maneira que isso o levava a enfrentar numerosas aventuras até se converter no melhor cavaleiro do mundo, para o que era necessário também possuir 
uma série de virtudes inerentes, tais como a cortesia, o valor, a lealdade ou a mesura.

No que diz respeito ao amor, Amadis era o perfeito namorado de Oriana e simbolizava a fidelidade, a pureza nos sentimentos amorosos, inquebrável apesar das adversidades, e o cavaleiro capaz de resistir às tentações da carne mesmo ignorando o seu dever como tal. Como diz Fernando Gómez Redondo ${ }^{8}$, Amadis surgira não só para ultrapassar os modelos heroicos de Tristão e Lançarote, mas também para demonstrar que, através do amor cortês, era possível atingir a perfeição sem utilizar filtros, nem magos, nem manter relações adúlteras. Não obstante, de acordo com a maioria dos investigadores, ao longo do livro IV do Amadis de Gaula, nota-se como Rodríguez de Montalvo, insatisfeito com o modelo heroico amadisiano, se opõe a ele e à cavalaria arturiana e cortês que representava, ao menos assim o manifestaram José Amezcua ou Samuel Gili Gaya9. E tanta é a sua oposição àquele mundo que decide mudar de estratégia narrativa a partir de então e começa a preparar a sucessão geracional na figura de Esplandião.

Mas para isso, precisava antes de mostrar a decadência do pai, o qual irá perdendo transcendência à medida que avança o quarto livro. Reflexo deste retrocesso é o imenso fracasso que o herói obterá em determinadas aventuras, tais como a impossibilidade de conseguir uma espada mágica na Pena da Donzela Encantadora $^{10}$, ou a incapacidade para acabar com o mago Arcaláus na Montanha Defendida durante o resgate do rei Lisuarte, feitos ambos que estavam reservados para Esplandião e que servem para pôr de manifesto o declínio de Amadis como cavaleiro, cuja função social ficará reduzida a partir de agora à do bom governante. Este declive é ainda mais notório na derrota que sofre o pai por parte do seu filho no passo de armas que estabelece o primeiro numa ponte, mostrando ao mesmo tempo a inutilidade de costumes próprias do universo arturiano com ideais que se consideravam agora desadequados.

${ }^{8}$ GÓMEZ REDONDO, Fernando. Historia de la prosa medieval castellana. Madrid: Cátedra, 1999, vol. II, p. 1563.

9 AMEZCUA, José. “La oposición de Montalvo al mundo del Amadís de Gaula”. NRFH, 21 (1972), pp. 320-337. Veja-se também Samuel GAYA, Gili. "Las Sergas de Esplandián como crítica de la caballería bretona". BBMP, 23 (1947), pp. 103-111.

${ }^{10}$ ALVAR, Carlos. De los caballeros del Temple al Santo Grial. Madrid: SIAL ediciones, 2010, p. 270. Palavras que Grasandor dirige a Amadis: "Dexemos esto para aquel donzel que comiença a subir donde vós descendís" (RODRÍGUEZ DE MONTALVO, Garci. Amadís de Gaula. Ed. Juan Manuel Cacho Blecua. 3. ed. Madrid: Cátedra, 1996, p. 1708). 
Para Esplandião não havia dúvida que a origem da decadência do seu pai não fora outra do que o seu desejo de fazer prevalecer as recompensas mundanas à salvação eterna, tal e como ele próprio diz:

\begin{abstract}
si las grandes cosas que mi padre con tanto esfuerço de su muy esforçado coraçón, y no menos peligro de su vida, passó fueran empleadas en servicio de aquel Señor que tan estremado entre tantos buenos le hizo en este mundo, no pudiera ser hombre ninguno igual ni semejante a la su virtud y gran valentía; pero él ha seguido con mucha afición más las cosas del mundo perecedero que las que siempre han de durar (I, II, 127). ${ }^{11}$
\end{abstract}

Contudo, apesar da perda de relevância do pai no quarto livro de Amadis e nas Sergas de Esplandião, o escritor de Medina del Campo, mais do que condenar ou castigar, tratará de regenerar e integrar a antiga cavalaria mundana de Amadis na nova cavalaria celestial dirigida por Esplandião, fazendo com que o primeiro ajude o segundo na conversão dos inimigos infiéis bem como na guerra santa ${ }^{12}$. Desta forma, não é inusitado ver Amadis assumir o comando da expedição contra os turcos ou participar numa das batalhas decisivas na cidade de Constantinopla, onde, ainda por cima, salva a vida do seu próprio filho, completando-se desta maneira, por um lado, a reabilitação do mundo amadisiano, e, por outro, a nova orientação do romance para uma linha temática baseada tanto na guerra, como na religião. E é aqui que o perfil de Esplandião se ajusta às mil maravilhas: um novo herói que representa os valores éticos e religiosos que circulavam então na corte dos Reis Católicos, um cavaleiro cristão ou miles Christi que encarna os ideais desta nova época dominada sob a ideia da cruzada, onde as empresas militares, além de ter um carácter mais colectivo, já não consistem em simples aventuras, mas sobretudo na defesa da Cristandade dos inimigos infiéis. Esta última ideia relacionase com o momento histórico que vive a Europa nos finais do século XV, cuja segurança estava a ser ameaçada pela expansão imparável do império otomano, o qual tinha conquistado Otranto em 1480, sem esquecer que no horizonte ainda estava muito presente a dolorosa perda de Constantinopla, em 1453.

De acordo com o exposto anteriormente, a ação das Sergas terá na figura de

\footnotetext{
${ }^{11}$ SALES DASÍ, Emilio José. "La heroica trayectoria literaria del caballero Amadís de Gaula". Amadís de Gaula: quinientos años después. Estudios en homenaje a Juan Manuel Cacho Blecua. Eds. José Manuel Lucía Megías e Ma Carmen Marín Pina. Alcalá de Henares: Centro de Estudios Cervantinos, 2008, pp. 743.

${ }^{12}$ RODRÍGUEZ DE MONTALVO, Garci. Sergas de Esplandián. Ed. Carlos Sáinz de la Maza. Madrid: Castalia, 2003, p. 59.
}

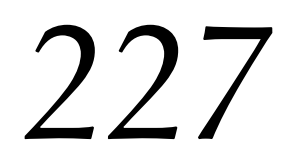


Esplandião um protagonista quase exclusivo, uma personagem cujo principal objetivo, além de procurar a salvação da alma, será a mesma que procuravam conseguir os monarcas, isto é, a unidade do país, a expansão da fé e a conquista de terras governadas por muçulmanos. Como consequência do profundo sentido religioso que permeia esta obra, o amor fica num segundo plano, quase esquecido, pelo menos até ficar resolvido o aspecto militar com o triunfo coletivo da Cristandade sobre os pagãos. Este oblívio, parece sugerir que Montalvo não se sentia à vontade com a relação amorosa mantida entre o protagonista e Leonorina, filha do imperador de Constantinopla, como se fosse um obstáculo para a sua intenção didática.

Longe do ardor e dos excessos que tinha caracterizado a cavalaria anterior, agora a retórica amorosa é muito mais contida, fria, sem interesse no desenvolvimento da história. Tudo isso porque Esplandião representa um ser muito mais espiritual, que, consciente do seu labor messiânico no mundo, decide manter a sua castidade até ao casamento com Leonorina, convertendo-se, depois dessa união, no novo imperador grego.

Alinhado na mesma vertente religiosa, embora muito mais ortodoxo do ponto de vista cristão, encontra-se o livro sexto de Amadis de Gaula, conhecido como Florisando (1510), do clérigo sevilhano Ruy Páez de Ribera. Preocupado tanto pela verosimilhança da história como pela ideia de romper com os excessos do universo de Rodríguez de Montalvo, perante o qual sentia uma grande aversão, o autor não hesita em criar um novo modelo de identidade heroica baseado nas virtudes cavaleirescas, mas também no estrito cumprimento das diretrizes religiosas dos inícios do século XVI.

Ao mesmo tempo, Ribera desloca o centro de poder desde Constantinopla até Roma, uma cidade com uma simbologia cristã mais do que evidente. De igual modo, concede o protagonismo do romance, não a um descendente direto da linhagem de Amadis, senão a um sobrinho deste último, o príncipe de Cantaria D. Florisando, filho do rei D. Florestão, deixando de lado Esplandião e seu filho Lisuarte. Segundo Fernando Gómez Redondo, com esta eleição Páez de Ribera pretendia eliminar qualquer possível contaminação com as personagens que tinham estado em contato com o mundo da magia ${ }^{13}$. E eis outro dos elementos sobre os que o autor dirige boa parte das suas críticas, posto que não concorda em absoluto com a graciosa utilização que Montalvo faz da arte mágica nem da maravilha, cuja

${ }^{13}$ GÓMEZ REDONDO, Fernando. Historia de la prosa de los Reyes Católicos: El umbral del Renacimiento. Madrid: Cátedra, 2012. Vol. II, p. 1821.

\section{8}


aparição é uma constante no Amadis . Assim, quase logo no início da obra, procede-se ao Desencantamento da Ínsula Firme onde estavam os protagonistas das Sergas de Esplandião, que tinham sido encantados pela sábia Urganda nos últimos capítulos. Também não é estranho neste sentido que nos deparemos amiúde com extensos discursos condenando o uso da magia e desacreditando, ao mesmo tempo, encantadores e feiticeiros. Agora tudo quanto tem a ver com o que escapa à compreensão humana é interpretado sob uma perspectiva cristã e atribuído, por isso, à presença de artes diabólicas.

Tendo em conta esta nova tendência mais religiosa, o protagonista vai receber uma educação diferente, mais de acordo com o seu caráter ascético, junto de um ermitão, com quem aprende a ler ou escrever, entre outras muitas coisas, mas não o uso das armas, que chegará a manejar pois fazia parte da sua própria natureza. Desta maneira, a maior parte das suas aventuras, ao invés de ter como resultado um benefício pessoal, vai estar destinada à defesa da única fé verdadeira, seriamente ameaçada perante o avanço turco no este da Europa. Como resposta à vertente realista de Ruy Páez de Ribera ${ }^{14}$, surge o fundamental contributo para o género cavaleiresco do escritor Feliciano de Silva ${ }^{15}$, natural da vila castelhana de Ciudad Rodrigo e mais conhecido por ter sido o continuador da Celestina de Fernando de Rojas ${ }^{16}$. Além deste livro, Silva compôs até cinco continuações do ciclo amadisiano publicadas por esta ordem: Lisuarte de Grécia (1514), Amadis de Grécia (1530), e as quatro partes do Florisel de Niquea, a primeira e a segunda publi-

\footnotetext{
${ }^{14}$ José Manuel Lucía Megías denomina "proposta realista" a criada pelo escritor Ruy Páez de Ribera. (LUCÍA MEGÍAS, José Manuel e SALES DASÍ, Emilio José. Libros de caballerías castellanos (siglos XVI-XVII). Ed. Del Laberinto. Colección Arcadia de las Letras, 2008, pp. 73-77).

${ }^{15}$ Os estudos mais atuais sobre Feliciano de Silva pertencem a SALES DASÍ, Emilio José. "Feliciano de Silva, aventajado "continuador" de Amadises y Celestinas", Actas del Congreso Internacional. Salamanca (Talavera de la Reina), Toledo (La Puebla de Montalbán), 27 de septiembre a 1 de octubre de 1999. Eds. F. B. Pedraza, R. González e G. Gómez, Cuenca: Universidad de Castilla-La Mancha, 2001, pp. 403-414; "Las continuaciones heterodoxas (el Florisando de Páez de Ribera y el Lisuarte de Grecia de Juan Díaz) y ortodoxas (el Lisuarte y el Amadís de Grecia de Feliciano de Silva) del Amadís de Gaula”. Edad de Oro, 21, 2002, pp. 117-152; “Feliciano de Silva”, Gran Enciclopedia Cervantina. No prelo, na Editorial Castalia-Centro de Estudios Cervantinos; "El ciclo de Amadís de Gaula", Gran Enciclopedia Cervantina, Madrid, Castalia, 2005, vol. I, pp. 439-469. Também são interessantes os seguintes trabalhos: MARTÍN LALANDA, Javier. "El ciclo de Florisel de Niquea [1532-1535-1551] de Feliciano de Silva", Edad de Oro, 21, 2002, pp. 153-176; MARTÍN ROMERO, José Julio. "El debate sobre Lucrecia en la obra de Feliciano de Silva". e-Humanista, vol. 16, 2010, pp. 99-126.

${ }_{16}$ Veja-se a este respeito a edição de Consolación Baranda da Segunda Celestina, de Feliciano de Silva, com prólogo de Fernando Arrabal, Madrid: Cátedra, 1988.
} 
cadas juntas em 1532, e a terceira e quarta partes impressas de forma isolada em 1535 e 1551, respetivamente.

A principal preocupação deste autor, sobretudo nos primeiros livros, consistirá em tratar de restaurar o perdido espírito cavaleiresco da obra de Montalvo, voltando a uns esquemas narrativos baseados na fantasia e na aventura, mas sem a carga política e religiosa do escritor medinês. Por isso, além de recuperar o cenário grego situando a defesa de Constantinopla do ataque infiel no centro da ação, esforça-se por continuar a ordem da linhagem de Amadis de Gaula, que tinha sido quebrada no Florisando, partindo do ponto em que tinham ficado as Sergas de Esplandião.

Deste modo, a trajetória vital dos heróis volta a girar ao redor dos feitos de armas e das peripécias amorosas, de tal maneira que os cavaleiros procuram de novo ganhar fama e estender a sua glória pela geografia romanesca com a finalidade de atingir, em última instância, o amor de uma figura feminina e, também, subir na hierarquia social e atingir a salvação eterna.

Longe de qualquer propósito doutrinal, Feliciano de Silva utiliza o género cavaleiresco como um campo aberto para a experimentação narrativa, tanto é assim que tudo parece ter cabimento na sua escrita. Assim, por exemplo, além de composições poéticas, inserem-se recursos, motivos e argumentos provenientes tanto do romance sentimental quanto do romance pastoril, os episódios de caráter humorístico são cada vez mais habituais, enchendo as histórias de momentos de grande diversão. Algo similar acontece com o puramente lúdico, cuja presença, seja enquanto invenções, seja como representações teatrais, vai sendo maior, em parte, porque reflete o mundo festivo dos espetáculos cortesãos, tão na moda nas primeiras décadas do século XVI.

Não obstante, se há um aspecto que sobressai sobre o resto, é o da presença cada vez mais habitual do mundo da magia e da maravilha. Ao contrário do que acontecia no Florisando ou naquelas outras obras adstritas à linha mais realista dos livros de cavalarias, agora o autor deleita-se na narração de montes de provas cavaleirescas, nas quais muitas vezes os sábios encantadores, que estão cada vez mais à disposição dos senhores a quem servem, agem com uma única finalidade: deleitar e entreter os seus hóspedes. Assim acontece, por exemplo, na Ínsula dos Xímios, onde Urganda a Desconhecida e Alquife, após uma série de encantamentos e de acontecimentos extraordinários, fazem com que os protagonistas tenham a oportunidade de conhecer a biblioteca do segundo, em cujo interior se achavam os

\section{0}


livros de profecias da saga amadisiana completa. A profusão de personagens, a inclusão de dúzias de aventuras e situações também farão com que esta "proposta experimental" do escritor de Ciudad Rodrigo, como a chama o professor José Manuel Lucía Megías ${ }^{17}$, se converta no caminho a seguir por parte dos futuros escritores de histórias cavaleirescas, servindo de ponte ao mesmo tempo entre o paradigma inicial idealista e o de entretenimento, que corresponde à última fase evolutiva do género cavaleiresco, representado, entre outros, pelos ciclos literários de Espejo de príncipes y cavalleros (I, 1555- II, 1580- III, 1587- IV, post. 1623), e do Belianis de Grécia (I-II, 1547- III-IV, 1579), ou, no âmbito português, pelas quatro continuações do Palmeirim de Inglaterra, de Diogo Fernandes e de Baltazar Gonçalves Lobato.

Nestas obras, que procuram evadir-se da realidade, o que interessa é deleitar o público através da narração de aventuras mistas de erotismo, onde imperam a hipérbole e diversos acontecimentos da esfera do maravilhoso. Para atingir este objetivo, os autores baseiam-se na proliferação de centenas de peripécias, na multiplicação de personagens e, portanto, de fios narrativos, na ampliação e na arbitrariedade da geografia por onde deambulam os heróis, no transbordar da imaginação com especial destaque nos acontecimentos de caráter maravilhoso e, em fim, no exagero e na desmesura que não pretendem senão entreter e divertir o público leitor ou ouvinte.

Devido à excessiva presença dos elementos mágicos e sobrenaturais, que fazem com que as aventuras cavaleirescas sejam eminentemente maravilhosas, assistimos à decadência dos valores heroicos, pois aquelas aventuras são resolvidas quase sempre pela repentina aparição dos sábios encantadores, em cujas mãos se deixa o triunfo ou o fracasso dos cavaleiros que intervêm nas provas.

Como exemplo para ilustrar esta ideia pode servir o capítulo 56 da quinta parte do Palmeirim de Inglaterra, de Gonçalves Lobato, que fala da Aventura da Ilha de Marte. Nela, Clarisol de Bretanha, filho de Dom Duardos Segundo e de Camélia, há-de obter as armas de Marte porque só com elas poderá libertar do seu encantamento as princesas que se achavam fechadas no Castelo das Fúrias. Assim, Clarisol encaminha-se decidido para a superação deste obstáculo. Num primeiro momento, após o som de uma trombeta tocada por um anão, Clarisol vence um

\footnotetext{
${ }^{17}$ Esta "proposta experimental" seria uma segunda resposta ao paradigma inicial de caráter idealista criado por Rodríguez de Montalvo nos cinco livros de Amadis de Gaula. Sobre esta denominação, veja-se LUCÍA MEGÍAS, José Manuel e SALES DASÍ, Emilio José. Libros de caballerías castellanos (siglos XVI-XVII). Ed. Del Laberinto. Colección Arcadia de las Letras, 2008, pp. 77-80.
} 
cavaleiro que lhe sai ao caminho vindo do interior de uma torre e ganha um punhal mágico com o qual logra atravessar um rio caudaloso, porque com ele faz desaparecer os numerosos monstros que saem do interior das suas águas. Mais à frente, sobe por uma rocha e penetra numa caverna que o conduz até um castelo quadrado onde se vê forçado a lutar, sucessivamente, contra o ciclope Polifemo, dois tigres e um gigante, até acabar por chegar a uma sala onde, por sua vez, tem de se confrontar com os melhores cavaleiros da Antiguidade Clássica: Teseu, Jasao, Hércules, Ajax, Aníbal, Lépido, Eneias, Diómedes, Heitor, Deifobo, Troilo e Aquiles. Depois de vencer cada um deles e de receber umas armas novas e uma "poma de água" com propriedades revitalizantes das mãos de Marte, Clarisol luta corpo a corpo com este último. Ultrapassada esta derradeira dificuldade, Clarisol faz-se ao final com as armas do deus e a faca de Teseu, sem as quais era impossível salvar as princesas do seu encantamento.

Como se pode ver através deste exemplo, a maravilha converte-se no fio condutor das aventuras. Deste modo, os heróis ficam paulatinamente sem capacidade de decisão, perdem a sua essência e a sua vontade de ação, produzindo-se uma desvalorização progressiva dos valores heroicos. Agora os protagonistas, convertidos em estereótipos, perdem ímpetu guerreiro e já não se caracterizam pelas virtudes propriamente cavaleirescas, tais como a firmeza, a fortaleza, a grandeza de espírito, a nobreza ou o valor, de tal maneira que deixam de ser seres excecionais e esforçados à procura de grandes façanhas para impor a ordem, destacando-se, agora, mais pelos seus dotes retóricos nas relações que mantêm com as suas respetivas damas. Os valorosos cavaleiros transformam-se, assim, em personagens sentimentais preocupadas, quase exclusivamente, com o amor, daí que ganhem protagonismo elementos como as letras, os motes, as danças e outros jogos cortesãos.

E como resposta à perda dos valores heroicos desta literatura de cavalarias de entretenimento, surge uma obra como o Quixote, na qual Miguel de Cervantes tratará de, entre outras coisas, reivindicar e recuperar o heroísmo da primitiva cavalaria, aquela defendida por Amadis de Gaula, o espelho, não o esqueçamos, sobre o qual se reflete o herói cervantino, quem fala em muitas ocasiões da necessidade de voltar aos tempos gloriosos do passado, como quando diz:

\section{2}


Sancho, amigo, has de saber que yo nací, por querer del cielo, en esta nuestra edad de hierro, para resucitar en ella la de oro, o la dorada, como suele llamarse. ${ }^{18}$

Mas a reivindicação de Cervantes, como sabemos, não vai ter o eco desejado, entre outras coisas porque naquela altura, nos princípios do século XVII, o espaço deixado pela desaparição do modelo heroico estava a ser preenchido pelo novo sujeito da ficção moderna, isto é, o pícaro, ou como quiseram chamar-lhe alguns, o anti-herói ${ }^{19}$. Mas este é um tema que será analisado no seguinte trabalho.

${ }^{18}$ CERVANTES, Miguel de. Quijote. Ed. Francisco Rico, Cervantes Virtual: Primera parte, Cap. 20: http://cvc.cervantes.es/literatura/clasicos/quijote/edicion/parte1/cap20/default.htm.

${ }^{19}$ SALINAS, Pedro. "El héroe literario y la novela picaresca española (Semántica e historia literaria)". Obras completas de Salinas, II. Ensayos completos. Madrid: Cátedra, 2007, pp. 1095-1107. Publicado originalmente na Revista de la Universidad de Buenos Aires, tercera época, IV, 1 (1946), pp. 75-84.

\section{3}

